\title{
Acute health effects of the Sea Empress oil spill
}

\author{
Ronan A Lyons, J Mark F Temple, Daphne Evans, David L Fone, Stephen R Palmer
}

\begin{abstract}
Study objective-To investigate whether residents in the vicinity of the Sea Empress tanker spill suffered an increase in self reported physical and psychological symptoms, which might be attributable to exposure to crude oil.
\end{abstract}

Design-Retrospective cohort study; postal questionnaire including demographic details, a symptom checklist, beliefs about health effects of oil and the Hospital Anxiety and Depression and SF-36 mental health scales.

Setting-Populations living in four coastal towns on the exposed south Pembrokeshire coast and two control towns on the unexposed north coast.

Patients-539 exposed and 550 unexposed people sampled at random from the family health services authority age-sex register who completed questionnaires.

Main results-Adjusted odds ratios for self reported physical symptoms; scores on the Hospital Anxiety and Depression and SF-36 mental health scales, in 1089 people who responded out of a possible 1585 (69\%).

Conclusions-Living in areas exposed to the crude oil spillage was significantly associated with higher anxiety and depression scores, worse mental health; and self reported headache (odds ratio $=2.35$, $95 \%$ CI $1.56,3.55)$, sore eyes (odds ratio = $1.96,95 \%$ CI $1.06,3.62$ ), and sore throat (odds ratio $=1.70,95 \%$ CI $1.12,2.60)$ after adjusting for age, sex, smoking status, anxiety, and the belief that oil had affected health. People living in exposed areas reported higher rates of physical and psychological symptoms than control areas. Symptoms significantly associated with exposure after adjustment for anxiety and health beliefs were those expected from the known toxicological effect of oil, suggesting a direct health effect on the exposed population.

(F Epidemiol Community Health 1999;53:306-310)

On the evening of the 15 February 1996, the Sea Empress laden with more than 130000 tonnes of light crude oil, ran aground on rocks at the entrance of Milford Haven harbour in south west Wales. Over the next week an estimated 72000 tonnes of crude oil and 360 tonnes of heavy fuel oil were released into the sea, contaminating around $200 \mathrm{~km}$ of coastline (fig 1) and causing strong smells and complaints of symptoms from residents of the coastal towns. Similar oil spills from the tankers Exxon Valdez ${ }^{1}$ and Braer $^{2}$ were fol- lowed by increases in physical and psychological symptoms in the general population. We undertook a population based retrospective cohort study to assess the acute physical and psychological health impact on the exposed population.

\section{Methods}

This study was commissioned four weeks after the incident. The exposed group was defined as people living on the most exposed south coast of Pembrokeshire (Milford Haven, Pembroke Dock, Tenby, and Saundersfoot) and the control group as similar but unexposed populations living on the north coast (Aberaeron and Fishguard) (fig 1).

Sample size calculations were based on the prevalence of symptoms in the control group reported in the Braer study. ${ }^{2}$ A sample of 814 in both exposed and control areas was required for 80 per cent power to detect a statistically significant $(p<0.05)$ doubling of prevalence of symptoms in the exposed group against a background prevalence of 3 per cent. To allow for non-response, random samples of 1000 adults (of both sexes aged 18 to 65 years old) were selected from each of the exposed and control areas using the Dyfed-Powys family health services authority age-sex register.

A questionnaire, with a retrospective health diary covering the four weeks immediately after the incident, was devised that also incorporated a symptom check list used in the Braer investigation, ${ }^{2}$ the Hospital Anxiety and Depression Scale (HAD), ${ }^{3}$ the mental health profile of the $\mathrm{SF} 36^{4}$ as well as a series of questions relating to beliefs about the effects of the oil spill on the environment, employment, health, and finances. The HAD Scale is widely used in clinical settings and was included in the study because of the marked excess of cases of clinically relevant anxiety and depression after the Exxon Valdez oil spill. ${ }^{2}$ The SF-36 mental health scale was included as population normative baseline data of SF-36 health scores was available from the Pembrokeshire health status study $^{5}$ undertaken in 1994 in randomly sampled adults from North $(\mathrm{n}=659)$ and South Pembrokeshire $(\mathrm{n}=597)$.

Questionnaires were mailed to people on the 4 April (seven weeks after the grounding of the tanker). Non-responders were sent a second questionnaire one month later. Nonresponders to the second questionnaire were contacted by telephone or visited at home by two of us (MT and DE) between 21 May and 18 June.

Statistical analysis was carried out using SPSS for Windows ${ }^{6}$ and Epi Info Logistic. Crude odds ratios for each self reported 

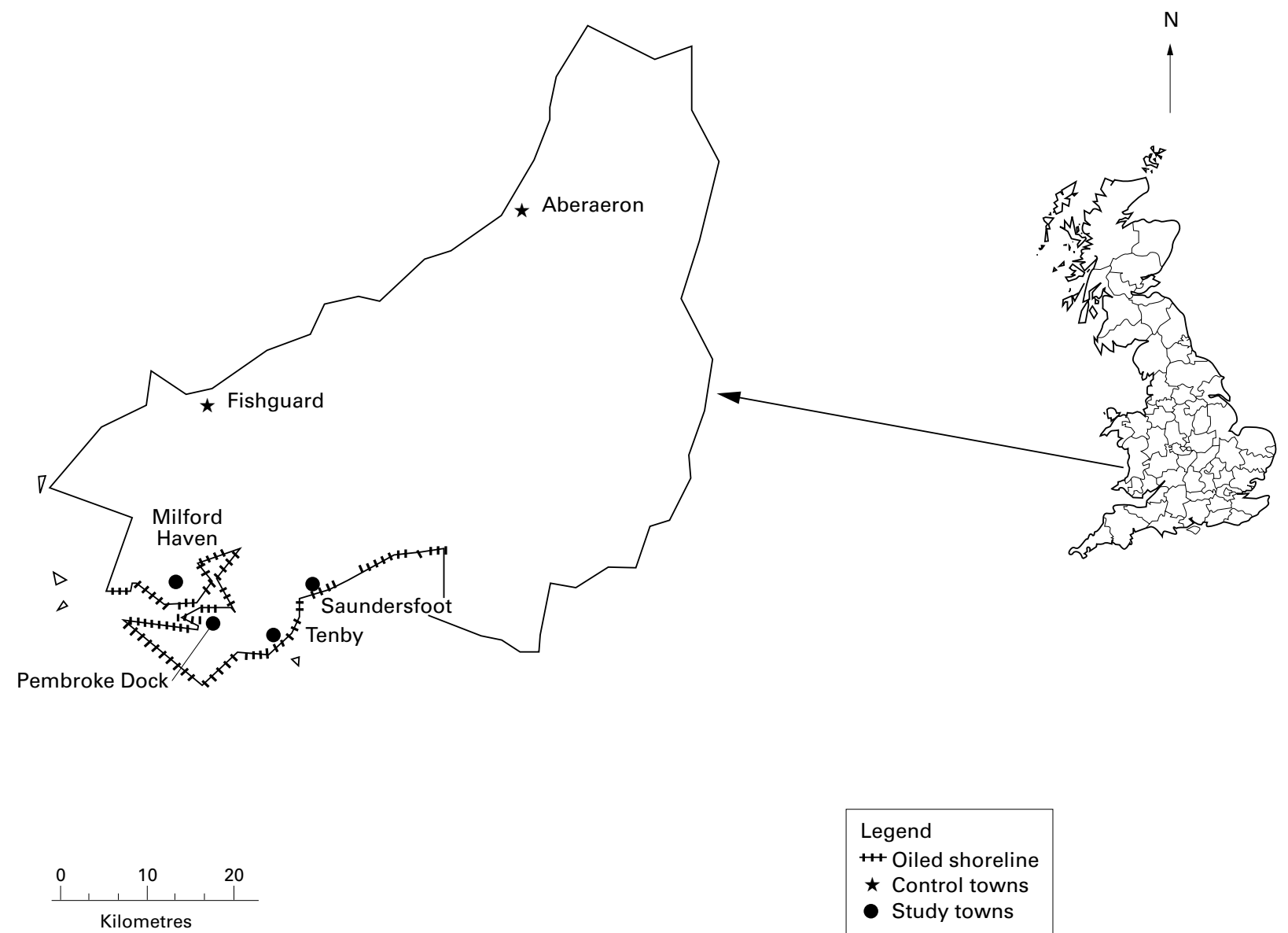

Figure 1 South west Wales showing extent of oil pollution and locations of study and control towns.

symptom in the exposed group were calculated with 95 per cent confidence intervals. Other categorical data were analysed using the $\chi^{2}$ test and continuous or ordinal data using either the $t$ test or non-parametric analysis of variance as appropriate. We carried out a forwards logistic regression analysis for each symptom in turn as the dependent variable, adjusting firstly for age, sex, HAD anxiety score, exposed/control status and smoking status, and secondly, including the health belief effect variable. The Hosmer-Lemeshow goodness of fit test ${ }^{7}$ was used to assess the effect of inclusion of the interaction term between anxiety and health belief effect in each model. Inspection of the data showed substantially high rates of reported illness in the exposed population on day one (16 February) (32 of 539 and 6 of 550 in exposed and control areas respectively). We considered this most likely represented biased recall, and therefore logistic regression analysis was undertaken after exclusion of those subjects.

The dates of exposure to oil were estimated from the Sea Empress Environmental Evaluation Committee's Report. ${ }^{8}$

To estimate the impact of the oil on self reported illness in the exposed population the expected rate of illness was calculated from the control population. The observed minus the expected was plotted for the two groups of exposed populations.

\section{Results}

After excluding those who were positively confirmed as not resident at their home address during the relevant period (211 and 204 people in control and exposed populations respectively), the overall response rate was 1089 of 1585 (69\%), with no significant difference between the exposed areas 68\% (539 of 796) and control areas $70 \%$ (550 of 789). There was no difference in mean age (exposed mean age 40.3 years, control 40.6 , range $18-65$ ) or the female to male ratios (both 5.5: 4.5) between the two groups. The reported prevalence of "ever smokers" (six months or more) was higher in the exposed area (245 of 539: $(45.5 \%) v 206$ of $550(37.5 \%)$ in the control area $\left.\chi^{2} 7.186 \mathrm{p}=0.0074\right)$, with no significant difference for current smoking $((28.2 \%) v$ $(25.3 \%), p=0.28)$.

In the population resident in the exposed area, responders reported excess symptoms and non-specific illness on the days when oil exposure was at its highest. Figure 2 demonstrates this for all self reported illness. The oil came ashore within the Haven by 17 February, but did no approach the western shoreline of Carmarthen Bay until 22 February. The oil persisted in the western Camarthen Bay until after the study period. In the Haven area daily rates of reported headache peaked on 16 February, the day after the initial oil spill, and 23 February, one to two days after the major secondary spill. 


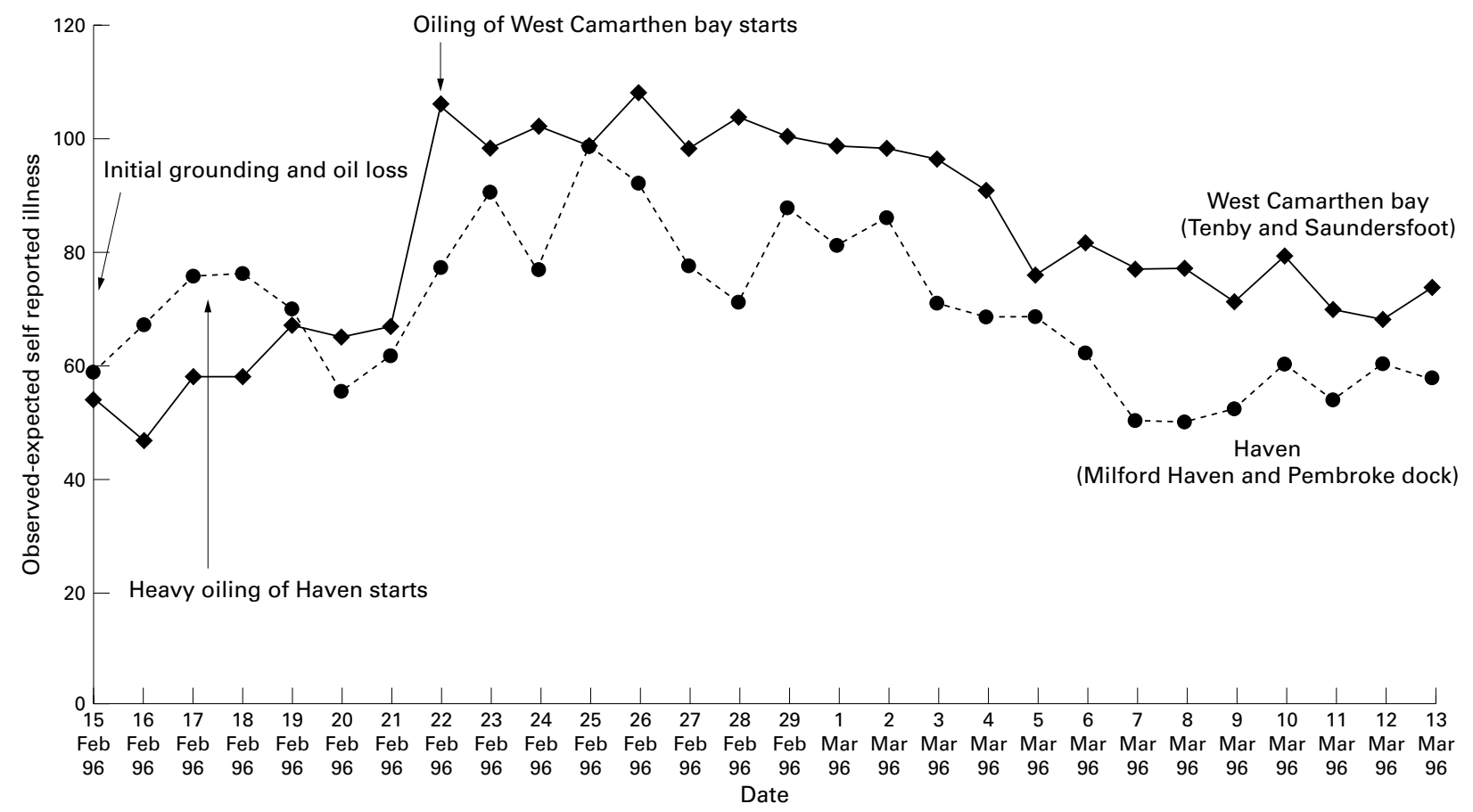

Figure 2 Excess (observed-expected) of self reported illness in area exposed to oil from Sea Express.

In the exposed area 55 of 539 responders reported consulting their general practitioner about any symptoms, within four weeks of the Sea Empress grounding, compared with 24 of 550 in the control area. (Yates's corrected $\chi^{2}=$ $12.95, \mathrm{df}=1, \mathrm{p}=0.0003)$. The crude relative risk of a person consulting was 2.34 (95\% confidence intervals 1.47 to 3.72 ). No data are available on consulting rates before the incident.

After standardising for age and sex using 1994 baseline normative data, the difference in expected mean SF-36 mental health score for exposed (75.14) and control groups (74.83) was not statistically significant. After the incident the mean SF-36 mental health score was significantly lower in the exposed population (73.44 $v 77.08, \mathrm{p}=0.002$ ) (table 1).

The four week period prevalence of almost all symptoms experienced between 16 February and 15 March was significantly increased in the exposed population (table 1). In the exposed area $39.3 \%$ reported one or more symptoms compared with $20.4 \%$ in the control areas $(p<0.001)$. The exposed population reported significantly more anxiety and depression, (HAD score $>10$ for each sub-scale) (table 1). Anxiety score $>10$ was associated with increased prevalence of most symptoms in both exposed and unexposed groups. In the exposed group 33 of $69(47.8 \%)$ anxious subjects reported general illness, compared with 84 of $419(20.0 \%)$ others $\left(\chi^{2}=13.3 \mathrm{df}=1\right.$ $\mathrm{p}=0.0003)$. In the control group the proportions were 9 of $50(18.0 \%)$ compared with 30 of $455(6.6 \%)$ (Fisher's exact test $\mathrm{p}=0.03)$. Adjustment for the effects of anxiety scores was made by logistic regression analysis. Odds ratios for all symptoms except diarrhoea, vomiting and skin blisters remained significantly raised in exposed subjects, adjusting for age, sex, HAD score and ever smoking status (table 2). The belief that the oil spill had affected their health was reported by 12 unexposed people $(2.4 \%)$ compared with $112(23.3 \%)$ of those exposed $(p<0.001)$. After inclusion of this

Table 1 Four week period prevalence of symptoms in exposed and unexposed population

\begin{tabular}{|c|c|c|c|c|c|c|c|}
\hline \multirow{2}{*}{$\frac{\text { Symptom }}{\text { Generally ill }}$} & \multicolumn{2}{|l|}{ Exposed } & \multicolumn{2}{|l|}{ Unexposed } & \multirow{2}{*}{$\frac{O / R s}{3.91}$} & \multirow{2}{*}{$\frac{95 \% C I}{2.63,5.85}$} & \multirow{2}{*}{$\frac{p \text { Value }}{<0.001}$} \\
\hline & $125 / 525$ & $(23.8 \%)$ & $40 / 541$ & $(7.4 \%)$ & & & \\
\hline Headache & $175 / 461$ & $(38.0 \%)$ & $66 / 469$ & $(14.1 \%)$ & 3.74 & $2.67,5.24$ & $<0.001$ \\
\hline Nausea & $68 / 419$ & $(16.2 \%)$ & $32 / 461$ & $(6.9 \%)$ & 2.60 & $1.63,4.16$ & $<0.001$ \\
\hline Vomiting & $15 / 396$ & $(3.8 \%)$ & $14 / 454$ & $(3.1 \%)$ & 1.24 & $0.55,2.77$ & 0.57 \\
\hline Diarrhoea & $41 / 407$ & $(10.1 \%)$ & $25 / 455$ & $(5.5 \%)$ & 1.93 & $1.11,3.35$ & 0.01 \\
\hline Sore eyes & $84 / 427$ & $(19.7 \%)$ & $27 / 457$ & $(5.9 \%)$ & 3.90 & $2.41,6.35$ & $<0.001$ \\
\hline Runny nose & $105 / 431$ & $(24.4 \%)$ & $62 / 470$ & $(13.2 \%)$ & 2.12 & $1.47,3.05$ & $<0.001$ \\
\hline Sore throat & $143 / 454$ & $(31.5 \%)$ & $58 / 471$ & $(12.3 \%)$ & 3.27 & $2.29,4.68$ & $<0.001$ \\
\hline Cough & $103 / 431$ & $(23.9 \%)$ & $53 / 466$ & $(11.4 \%)$ & 2.45 & $1.67,3.58$ & $<0.001$ \\
\hline Itching skin & $56 / 403$ & $(13.9 \%)$ & $26 / 455$ & $(5.7 \%)$ & 2.66 & $1.59,4.48$ & $<0.001$ \\
\hline Rash & $36 / 402$ & $(9.0 \%)$ & $16 / 453$ & $(3.5 \%)$ & 2.69 & $1.41,5.18$ & $<0.001$ \\
\hline Blisters & $6 / 389$ & $(1.5 \%)$ & $2 / 449$ & $(0.4 \%)$ & 3.50 & $0.63,25.55$ & 0.10 \\
\hline Shortness of breath & $56 / 408$ & $(13.7 \%)$ & $24 / 454$ & $(5.3 \%)$ & 2.85 & $1.68,4.86$ & $<0.001$ \\
\hline Weakness & $117 / 432$ & $(27.1 \%)$ & $70 / 469$ & $(14.9 \%)$ & 2.12 & $1.50,3.00$ & $<0.001$ \\
\hline Definite anxiety & $72 / 502$ & $(14.3 \%)$ & $51 / 511$ & $(10.0 \%)$ & 1.51 & $1.01,2.26$ & 0.03 \\
\hline Mean anxiety score & 5.44 SD 4.54 & (SE 0.186) & $4.82 \mathrm{SD} 4.21$ & (SE 0.203) & & & 0.036 \\
\hline Definite depression & $27 / 505$ & $(5.3 \%)$ & $20 / 520$ & $(3.8 \%)$ & 1.41 & $0.75,2.67$ & 0.3 \\
\hline Mean depression score & $3.33 \mathrm{SD} 3.83$ & (SE 0.142) & $2.70 \mathrm{SD} 3.23$ & (SE 0.171) & & & 0.049 \\
\hline Mean SF-36 mental health score & 73.4 SD 19.5 & (SE 0.869) & 77.1 SD 18.39 & (SE 0.814) & & & 0.002 \\
\hline
\end{tabular}


Table 2 Logistic regression odds ratios for symptoms in exposed population adjusted for age, sex, anxiety score, and smoking status

\begin{tabular}{lll}
\hline Symptom & Odds ratio $(95 \%$ CI) & p value \\
\hline Generally ill & $3.5(2.25,3.50)$ & $<0.0001$ \\
Headache & $3.93(2.70,5.71)$ & $<0.0001$ \\
Nausea & $2.41(1.44,4.03)$ & $<0.001$ \\
Vomiting & $0.97(0.40,2.34)$ & 0.95 \\
Diarrhoea & $1.56(0.86,2.83)$ & 0.14 \\
Sore eyes & $3.59(2.12,6.07)$ & $<0.0001$ \\
Runny nose & $1.97(1.33,2.91)$ & $<0.0001$ \\
Sore throat & $2.89(1.99,4.20)$ & $<0.001$ \\
Cough & $1.94(1.30,2.91)$ & $<0.001$ \\
Itching skin & $2.31(1.33,4.03)$ & $<0.01$ \\
Rash & $2.26(1.13,4.51)$ & 0.02 \\
Blisters & $5.99(0.69,52.0)$ & 0.10 \\
Shortness of breath & $2.31(1.27,4.19)$ & $<0.01$ \\
Weakness & $2.04(1.44,2.89)$ & $<0.001$ \\
\hline
\end{tabular}

Table 3 Logistic regression odds ratios adjusting for age, sex, smoking status, anxiety score, and health belief effect

\begin{tabular}{lll}
\hline Symptom & Odds ratio $(95 \%$ CI) & $\begin{array}{l}\text { Hosmer-Lemeshow } \\
\text { goodness of fit p value* }\end{array}$ \\
\hline Headache & $2.35(1.56,3.55)$ & $0.18(0.11)$ \\
Sore eyes & $1.96(1.06,3.62)$ & $0.85(0.002)$ \\
Sore throat & $1.70(1.12,2.60)$ & $0.15(0.01)$ \\
\hline
\end{tabular}

${ }^{\star}$ Goodness of fit $\mathrm{p}$ value without interaction term (anxiety $\times$ health effect belief) in the model.

variable in each logistic regression model, the odds ratios for headache $(\mathrm{OR}=2.35,95 \% \mathrm{CI}$ $1.56,3.55, \mathrm{p}<0.001)$, sore eyes $(\mathrm{OR}=1.97$, $95 \%$ CI $1.08,3.60, \mathrm{p}<0.03)$, and sore throat $(\mathrm{OR}=1.65,95 \%$ CI 1.08, 2.52, $\mathrm{p}<0.02)$ remained significantly increased (table 3 ). In each of these three models the interaction term of anxiety score and health effect belief significantly increased the goodness of fit.

\section{Discussion}

This is the first reported study of urban populations exposed to a large oil spill. In previous studies $^{12}$ the incident has occurred away from large centres of population. We found an increase in self reported psychological and physical symptoms in the exposed south Pembrokeshire population during the four weeks after the incident. Self reported headaches, sore eyes, and sore throats were significantly associated with exposure to crude oil after adjusting for age, sex, smoking status, anxiety, and health belief effects. The exposed population reported significantly more anxiety and depression measured by the Hospital Anxiety and Depression scale with mean SF-36 mental health scores 3.6 lower than the control population. The magnitude of this difference in the population mean mental health score is comparable to the difference between Pembrokeshire and the most socially disadvantaged areas of Wales as measured in the 1995 Welsh Health Survey. ${ }^{9}$

Before this excess of symptoms can be attributed to exposure to the oil spill it is necessary to consider possible biases in the study. Response rates were very similar in the exposed and control areas $(68 \% v 70 \%)$; the rate of headaches in control non-responders would have to be more than five times the rate in responders to render the difference in control and exposed populations non-significant. The main threat to the validity of our findings
KEY POINTS

- People living in towns exposed to the oil spill had significantly higher self reported illness including anxiety and depression than those living in control towns.

- After adjustment for the effect of anxiety score, age, sex, and smoking status significant associations remained with headache, sore eyes, and sore throat.

- Headache, sore eyes, and sore throat are the symptoms predicted to be associated with exposure to crude oil on the basis of known toxicological effects.

comes from recall and rumination bias leading to exaggeration of symptoms in the exposed population. This may explain the excess of illness reported by the exposed population on day one of the incident; very little oil escaped within the first 12 hours of the ship running aground. So the excess of symptoms recorded on the first day cannot be attributed to the effect of the oil. However, even when persons reporting illness on day one were excluded from the analyses, most symptoms were still significantly more common in the rest of the exposed group. Increased anxiety because of fear, or the potential impact on employment might be expected to affect the reporting of symptoms but the increased prevalence of many symptoms was found to be independent of anxiety score.

Predictably, a higher proportion of people in the exposed areas reported that they believed the oil spill had affected their health $(23 \% v$ $2 \%$ ) and it is possible that those with this belief would tend to over-report symptoms. Adjustment for its effect by removing rumination bias may give a more reasonable estimate of risk. Rates of headaches, sore eyes and sore throat still remained statistically higher in the exposed population. We conclude that after conservative allowances are made for bias, the physical health of the exposed group remained significantly worse than the control population. Had data on individual exposures been available a dose response relation would have strengthened this conclusion.

Is the higher prevalence of symptoms (after adjusting for anxiety and health belief effects) a direct effect of exposure to oil or to the detergents used in the clean up, or a non-specific response to an environmental threat? Perceived exposure to an environmental threat, may result in an excess of reported physical symptoms in the absence of a chemical effect. For example, in Worcester, UK in 1995 the water supply to 160000 people was contaminated with low doses of dioxanes. ${ }^{10}$ Within the group noticing an unusual taste to the water there was an excess of symptoms.

However, the distribution of the water supply was such that study subjects who did or did not notice an unusual taste were equally exposed to contaminated water. The authors concluded that the observed increase in reported symptoms was because of public anxiety caused by the incident rather than the 
direct effect of the exposure. In Texas more than 1000 people attended the emergency departments of hospitals after $40000 \mathrm{lb}$ of hydrofluoric acid was released into the atmosphere. ${ }^{11}$ High exposure was associated with an excess of physical symptoms but the presence of some physical symptoms was better explained by the degree of psychological distress. However, the physical symptoms significantly associated with exposure after adjusting for psychological distress were those for which there was a biologically plausible relation with hydrofluoric acid.

In our study, the increase in the reported prevalence of headaches, sore eyes, and sore throat after day one was independent of health beliefs and anxiety levels; these symptoms are compatible with both exposure to crude oil and to detergents (personal communication, Welsh National Poisons Unit). Furthermore, and importantly, our findings are similar to those found after the Braer oil spill in Shetland, Scotland in $1993 .^{2}$ The Braer study, based on 420 exposed people and 92 controls, reported significantly higher rates of headache, throat irritation, and itchy eyes particularly in the two days after the oil spill.

Little is known about the longer term psychological effects on the general population of coastal oil spills. One year after the Exxon Valdez oil spill in Alaska a survey of 599 people in 15 communities was carried out to measure psychological effects. ${ }^{1}$ Residents from high exposure communities were 3.6 times as likely to have generalised anxiety disorder, 2.9 times as likely to have post-traumatic stress disorders, and 2.1 times as likely to have a high depression score. A follow up study of the Braer oil spill reported significantly higher scores on the general health questionnaire in the exposed group $(23.6 \%$ v $3.4 \%$ above threshold scores for mental distress). ${ }^{12}$

In our study, the exposed groups also had significantly higher anxiety and depression scores as measured by the HAD scale and worse mental health as measured by the SF-36 mental health scale. ${ }^{3}$ Whether the psychological effects are because of a toxic effect of the oil or are a generalised response to an environmental disaster with potential impacts on health, employment, income, and perception of the environment is unknown. Given the experience of the Worcestershire water incident and the Texas hydrofluoric acid episode it would seem probable that much, if not all, of the psychological effect is a generalised response to environmental disasters. These studies suggest that in environmental incidents adjustment should be made for psychological effects and health beliefs, as we did in our study.

Overall this study shows that, like previous similar incidents, the Sea Empress oil spill resulted in higher levels of psychological and physical symptoms in the exposed populations of south Pembrokeshire. Even after adjusting for the psychological effects and health beliefs of residents, there was a significant association found between exposure and biologically plausible symptoms. The plausibility is based on the known toxicological effects of crude oil. The coherence of these results suggests that the association is causal, resulting in a direct health effect on the exposed population. It also suggests that the method used in our study to adjust for psychological effects and health beliefs should be considered for use in epidemiological studies in future major environmental incidents. Further studies are planned to assess whether there are any longer term sequelae after this incident.

Conflicts of interest: none.

1 Palinkas LA, Peterson JS, Russel J, et al. Community patterns of psychiatric disorders after the Exxon Valdez oil spill. Am F Psychiatry 1993;150:1517-23.

2 Campbell D, Cox D, Crum J, et al. Initial effects of the grounding of the tanker Braer on health in Shetland. The Shetland Health Study Group. BMF 1993;307:1251-5.

3 Zigmond AS, Snaith RP. The Hospital Anxiety and Depression Scale. Acta Psychiatr Scand 1983;67:361-70.

4 Ware JE, Sherbourne CD. The MOS 36 Items Short-Form Wealth Survey (SF-36): 1 . Conceptual framework and item Health Survey (SF-36): 1. Conceptual

5 Monaghan S. The Pembrokeshire Health Status Survey. South East Pembrokeshire Project: Technical Document 1,

6 Norusis MJ. SPSS for Windows Release 6.0. Chicago: Statistical Package for the Social Sciences, 1993

7 Dallal GE. LOGISTIC: A Logistic Regression Program for the IBM PC. The American Statistician 1988;42:272.

8 Sea Empress Environmental Evaluation Committee. The environmental impact of the Sea Empress oil spill. London: HMSO, 1997.

9 Welsh Office. 1995 Welsh Health Services. Cardiff: Welsh Office, 1996.

10 Fowle SE, Constantine CE, Fone D, et al. An epidemiological study after a water contamination incident near Worcester, England in April 1994. F Epidemiol Community Health 1995;50:18-23.

11 Dayal HH, Baranowski T, Li Y, et al. Hazardous chemicals: psychological dimensions of the health sequelae of a compsychological dimensions of the health sequelae of a com-
munity exposure in Texas. 7 Epidemiol Community Health munity exposure

12 Campbell D, Cox D, Crum J, et al. Later effects of grounding of tanker Braer on health in Scotland. BMF 1994;309: $773-4$. 